\title{
Ecosystem-Scale Effects of Nutrients and Fishing on Coral Reefs
}

\author{
Sheila M. Walsh ${ }^{1,2}$ \\ ${ }^{1}$ Scripps Institution of Oceanography, University of California, San Diego, La Jolla, CA 92093, USA \\ ${ }^{2}$ Environmental Change Initiative, Brown University, Box 1951- 167 Thayer Street, 214 MacMillan Hall, Providence, RI 02912, USA
}

Correspondence should be addressed to Sheila M. Walsh, sheila_walsh@brown.edu

Received 18 July 2010; Accepted 21 October 2010

Academic Editor: Kim Selkoe

Copyright (c) 2011 Sheila M. Walsh. This is an open access article distributed under the Creative Commons Attribution License, which permits unrestricted use, distribution, and reproduction in any medium, provided the original work is properly cited.

\begin{abstract}
Nutrient pollution and fishing are the primary local causes of coral reef decline but their ecosystem-scale effects are poorly understood. Results from small-scale manipulative experiments of herbivores and nutrients suggest prioritizing management of fishing over nutrient pollution because herbivores can control macroalgae and turf in the presence of nutrients. However, ecological theory suggests that the opposite occurs at large scales. Moreover, it is unclear whether fishing decreases herbivores because fishing of predators may result in an increase in herbivores. To investigate this paradox, data on the fish and benthic communities, fishing, and nutrients were collected on Kiritimati, Kiribati. Oceanographic conditions and a population resettlement program created a natural experiment to compare sites with different levels of fishing and nutrients. Contrary to theory, herbivores controlled macroalgae in the presence of nutrients at large spatial scales, and herbivores had greater effects on macroalgae when nutrients were higher. In addition, fishing did not increase herbivores. These results suggest that protecting herbivores may have greater relative benefits than reducing nutrient pollution, especially on polluted reefs. Reallocating fishing effort from herbivores to invertivores or planktivores may be one way to protect herbivores and indirectly maintain coral dominance on reefs impacted by fishing and nutrient pollution.
\end{abstract}

\section{Introduction}

Fishing [1-7] and nutrient pollution $[8,9]$ or both [10$14]$ are cited as the most important local causes of coral reef decline. It is difficult, however, to evaluate local fishing and nutrient effects independently because these factors are almost always confounded and large-scale experiments are infeasible. Results from theoretical and small-scale experimental studies (typically $<1 \mathrm{~m}^{2}$, four from 50 to $250 \mathrm{~m}^{2}$ [14]) suggest prioritizing management of herbivore populations because herbivores can control the effect of nutrients on macroalgal and turf abundance and nutrient enrichment alone is not sufficient to cause a phase shift from coral to macroalgal and/or turf algal dominance $[11,14,15]$. In order to apply these results and implement ecosystembased management, information is needed on (1) how fishing and nutrients interactively affect the fish and benthic communities, (2) the mechanisms by which fishing (rather than cages that exclude fish) and nutrients are linked to shifts to macroalgal and turf algal dominance, and (3) whether herbivores can control macroalgae and turf algae when nutrient enrichment occurs at spatial scales of $10 \mathrm{~s}$ of kilometers, the spatial scale of local nutrient pollution.

Our understanding of how fishing and nutrients interactively affect fish and benthic communities is informed by a large number of factorial experiments that examine effects of herbivores and nutrients on benthic communities [14] and observational studies of the effects of marine reserves or fishing on the fish and benthic communities $[1,2,4$, $5,7,15-20]$. A meta-analysis of factorial experiments that manipulated herbivores and nutrients suggests that low levels of herbivory are the primary factor increasing macroalgae on coral reefs but that nutrient enrichment can enhance this effect [14]. Nutrient enrichment, however, decreases turf algae in tropical systems when herbivores are present $[14,21]$. In contrast, reef-builders (corals and crustose coralline algae (CCA)) are more abundant when herbivores are present $[14,21]$. Nutrient enrichment affects corals and CCAs differently, just as it has different effects on macroalgae and turf algae. Corals are less abundant when nutrients are enriched [21], while CCA is more abundant when nutrients are enriched in the presence of herbivores [21]. Although 
there is a relatively good understanding of the effects of herbivores on algae, our understanding of the effects on corals is very limited because only one study to date is long enough to examine effects on coral recruitment [21].

No studies have factorialy manipulated fishing and nutrients and only limited inferences can be made from the results of experiments that use cages to reduce herbivory because it is unclear whether fishing also results in reduced herbivory. One hypothesis is that fishing removes top predators, indirectly increasing the abundance of herbivores and decreasing macroalgal and turf algal abundance through a trophic cascade [18-20]. There is limited evidence for trophic cascades on coral reefs probably because trophic linkages are diverse, some herbivores escape in size from predation, and some important herbivores, such as parrotfish, can be targets in mixed-gear coral reef fisheries [22]. Alternatively, fishing may first remove large, slow growing, late maturing fish and sequentially remove species with less vulnerable life histories [23]. In fisheries where these life history traits correspond well to specific trophic groups, this results in "fishing down the food chain" from top predators to carnivores to herbivores [24], which may increase macroalgal and turf algal abundance. Fisheries across a gradient of socioeconomic development show evidence of a transition from gillnets (nonselective) to spearguns (selective) to handlines (selective for predators/carnivores only) [25]. This suggests that more developed fisheries are more likely to cause a trophic cascade, while a fishery with a diversity of gear types may mask the effects of a trophic cascade by fishing simultaneously or sequentially down the food chain or size classes.

The relative importance of managing herbivore populations versus nutrient inputs depends on whether topdown control of macroalgae and turf algae, which has been shown in small-scale $\left(\sim 1 \mathrm{~m}^{2}\right)$ experiments, also occurs at large spatial scales. Using simple Lotka-Volterra models of nutrients, autotrophs, and consumers, Gruner et al. [26] predicted that top-down control should occur if herbivory increases proportionally with nutrient-induced increases in autotrophs. Therefore, top-down control could be an artifact of the small scale of an experiment if herbivores concentrate their grazing on small patches of nutrient enriched algae [14]. In contrast, empirical studies show that at larger spatial scales herbivores are less able to track resources because of increased resource heterogeneity or predation risk, suggesting that top down control will not be observed at large spatial scales [27-29]. Gruner et al. [26] found no association between the spatial scale of experiments and effect size of herbivores across 191 manipulative experiments; however, this may have been a result of comparing experiments across different ecosystems, over a small range of spatial scales $(<1$ to $\sim 400 \mathrm{~m}^{2}$ ), or with few predators.

A population re-settlement program and island-wake upwelling (the vertical transport of nutrients from deeper waters caused by a current flowing around an island) on Kiritimati Atoll, Line Islands, Kiribati (Figures 1 and 2), created a unique large-scale natural experiment to test the ecosystem-scale effects of fishing and nutrients. Kiritimati was permanently settled less than 150 years ago but resettlement of people from the capital, Tarawa $(\sim 3,000 \mathrm{~km}$ to the west), has caused rapid population growth $(66 \%$ increase from 1985 to 2005) [30]. Despite the recent population growth, Kiritimati remains largely undeveloped with artisanal fishing being the primary economic activity. Spatial variation in fishing pressure is not expected to be caused by the variation in fish abundance because the spatial pattern of fishing is a consequence of the government program, an exogenous factor unrelated to fishing resources. Therefore, greater inference can be made about fishing as a factor in the observed ecosystem structure than in most studies along fishing gradients. Similar inferences can be made about the role of nutrients because island-wake upwelling is an exogenous factor that creates a zone of higher nutrients and primary production on the northwestern side of the island (Figure 2, see Figures S1, S2 in Supplementary Material available online at doi: 10.1155/2011/187248 for in situ data on currents, sea surface temperature, fluorescence, and phosphate). Importantly, fishing, and nutrients are not confounded because settlement has mostly occurred along the northern coastline and nutrient pollution from land is low because rainfall is low, there are no industrial activities, bird populations are lower near villages and, overall, the human population is relatively low $[7,31,32]$.

Recent studies of the reefs in the upwelling zone on Kiritimati show that the water chemistry was more characteristic of nearshore reefs than oceanic reefs and had higher concentrations of microbes, which were associated with coral disease and fewer coral recruits [32]. These reefs also had fewer top predators and corals and more planktivores and macroalgae and turf algae compared to nearby unfished reefs (Palmyra Atoll and Kingman Reef) in less productive waters in the northern Line Islands [7]. However, the relative importance of fishing and nutrients is still uncertain because fishing was confounded with oceanographic conditions in previous studies of coral reefs in the northern Line Islands across a gradient of fishing pressure from unfished Palmyra and Kingman Atolls to fished Tabuaeran and Kiritimati (note that only sites in upwelling zone of Kiritimati were studied) $[7,32]$. Here, I took advantage of the spatial variation in fishing and nutrients within Kiritimati to disentangle the effects of fishing and nutrients on coral reefs at the ecosystem scale.

In sum, I expected that reefs with higher nutrients should have a higher abundance of macroalgae, turf algae, herbivores, and planktivores, while fished reefs should have a lower abundance of top predators and carnivores (Table 1). I expected that fishing down the food chain and size classes should be the best supported mechanism for the pattern in fish abundance because Kiritimati has a fishery with a mix of gear types (Table 1). In addition, I expected that herbivores should not exhibit top down control of macroalgae and turf algae in the presence of nutrients because fishing and nutrients enrichment on Kiritimati occur at large spatial scales. I tested my expectations for the effects of nutrients and fishing on the abundance of fish and benthic community groups using a natural factorial experimental design (Figures 1 and 2). This natural experiment replicated small-scale manipulative experiments at a larger spatial scale and measured effects for a greater number of ecosystem 


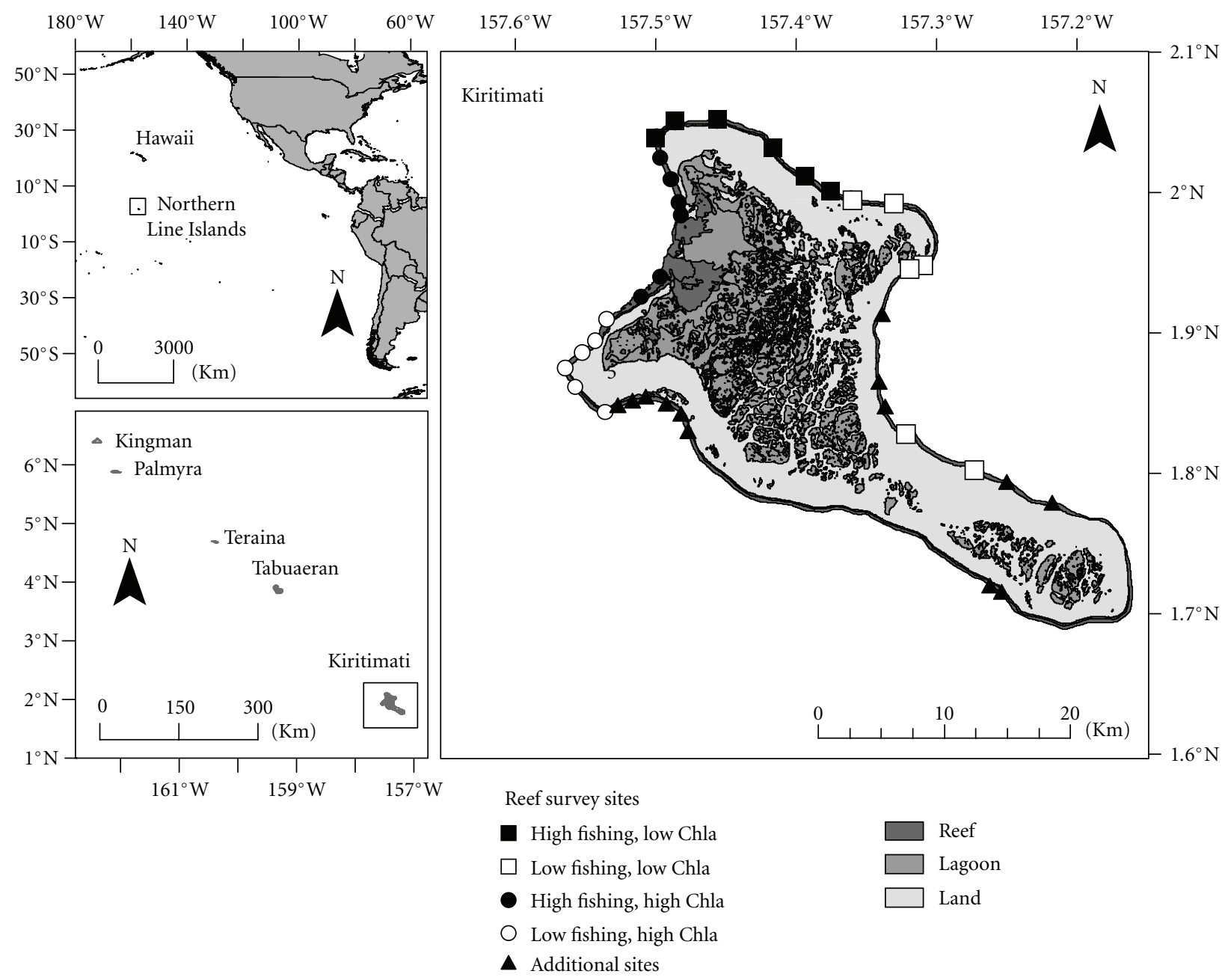

Figure 1: Location of ecological survey sites on Kiritimati, Line Islands, Republic of Kiribati. Twenty-four sites were chosen to create a balanced natural factorial experimental design to test the effect of nutrients (proxied by chlorophyll- $a$ ) and fishing on the fish and benthic communities. An additional 13 sites were chosen to capture the full fishing gradient and test mechanisms.

components. I then investigated the ecological mechanisms associated with fishing and top-down control of macroalgae and turf algae at large spatial scales using regression basedmethods. These tests allowed for interpretation of the effects of fishing and nutrients on coral reef ecosystem structure in the context of ecosystem-based management [33].

\section{Methods}

2.1. Study Sites. I surveyed the benthic and fish communities at 37 sites in the fore-reef habitat (Figure 1) from July 20 to August 10, 2007. Of these, 24 were chosen using $a$ priori knowledge of fishing and chlorophyll-a concentrations, based on the spatial distribution of upwelling and human settlements, to create a balanced factorial design with two factors (fishing and chlorophyll-a) and two levels of each factor (high and low). An additional 13 sites were chosen to capture the full fishing gradient and allow for tests of mechanisms using regression-based methods. These additional sites were not included in analyses of the natural factorial experiment because their inclusion would cause fishing and chlorophyll- $a$ to be correlated; however, they could be used in the analysis of mechanisms linking changes in the fish community and chlorophyll- $a$ to changes in the benthic community because chlorophyll- $a$ was shown to not affect top predator or herbivore biomass (see results and Table S4 in Supplementary Material results of twoway ANOVA comparing effects of fishing and chlorophyll$a$ on fish biomass), and herbivore biomass and chlorophyll$a$ were not significantly correlated across the full range of sites (Spearman Correlation, rho $=-0.25, P=.14$ ). Sites were no less than $1 \mathrm{~km}$ apart (with one exception), and exact locations were chosen haphazardly. No sites were surveyed on the south central coast due to a lack of roads, the distance from the harbor, and large waves. Data on chlorophyll- $a$ and fishing were estimated for each site using remote sensing and household survey data, respectively (Figure 2).

\subsection{Data Collection}

2.2.1. Benthic Cover. The percent cover of major benthic taxonomic groups [coral, CCA, turf algae, macroalgae, and 


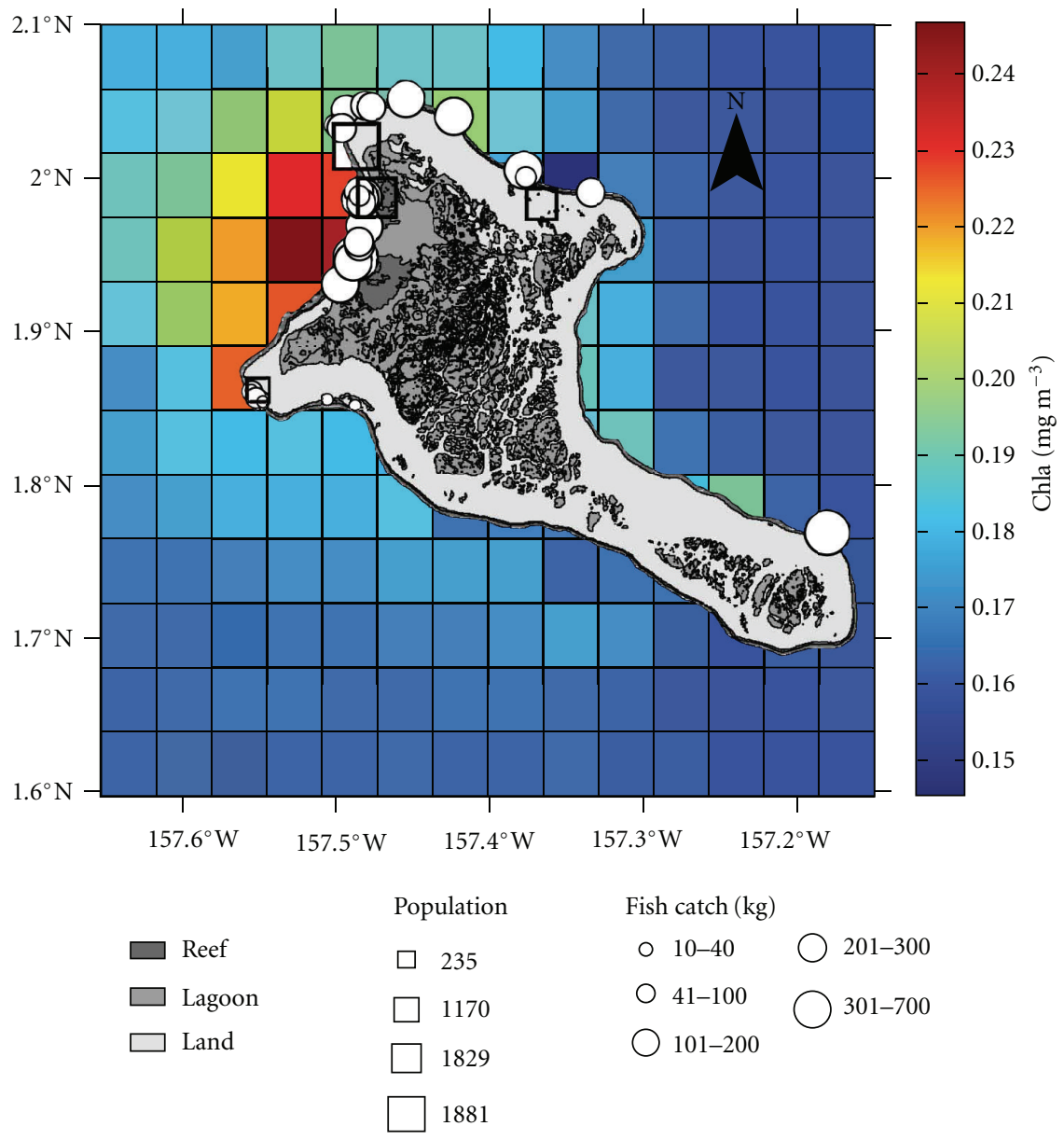

FiguRE 2: Chlorophyll- $a$ (a proxy for nutrients) and fishing conditions. Island-wake upwelling in the northwest results in higher chlorophylla concentrations (September 16, 2002 to August 16, 2007 monthly average values). Fishing trips (represented as circles) cluster near the villages (represented as squares).

TABLE 1: Hypotheses for independent effects of nutrients and fishing*.

\begin{tabular}{|c|c|c|c|c|c|c|c|}
\hline \multirow[t]{3}{*}{ Dependent } & \multirow[t]{3}{*}{ Nutrients } & \multicolumn{6}{|c|}{ Fishing } \\
\hline & & \multirow[t]{2}{*}{$\mathrm{TC}$} & \multirow[t]{2}{*}{ SCC } & \multicolumn{2}{|c|}{ FDFC } & \multicolumn{2}{|c|}{ FDSC } \\
\hline & & & & Low & High & Low & High \\
\hline \multicolumn{8}{|c|}{ Fish Community } \\
\hline Top Predators & + & - & $\mathrm{NA}$ & - & - & - & - \\
\hline Carnivores & + & - & NA & - & - & $-/+$ & - \\
\hline Planktivores & + & + & NA & NR & - & $-/+$ & - \\
\hline Herbivores & + & + & NA & NR & - & $-/+$ & - \\
\hline Large-bodied & + & NA & - & NA & NA & - & - \\
\hline Small-bodied & + & NA & + & $\mathrm{NA}$ & NA & NR & - \\
\hline \multicolumn{8}{|c|}{ Benthic Community } \\
\hline Coral & - & + & $-/+$ & NR & - & $-/+$ & - \\
\hline CCA & - & + & $-/+$ & NR & - & $-/+$ & - \\
\hline Turf & + & - & $-/+$ & NR & + & $-/+$ & + \\
\hline Macroalgae & + & - & $-/+$ & NR & + & $-/+$ & + \\
\hline
\end{tabular}

\footnotetext{
${ }^{*}$ This table shows the predicted response of fish trophic and benthic taxonomic groups to nutrients and fishing. Fishing may affect the fish and benthic community through four mechanisms: (1) trophic cascades (TC), (2) size class cascades (SCC), (3) fishing down the food chain (FDFC), and (4) fishing down the size classes (FDSC). Positive responses are indicated by + , negative responses by - , and ambiguous responses by $-/+$. No response is NR. Not applicable is NA. Predictions for responses to FDFC and FDSC are separated by low and high fishing pressure to distinguish between responses due to sequential fishing from high to low trophic levels or large-to small-bodied fishes.
} 
other (see Table S1 in Supporting Information for assignments of benthic taxa to groups)] was measured using the photoquadrat method along two $25 \mathrm{~m}$ transects, separated by approximately $10 \mathrm{~m}$ at $10-12 \mathrm{~m}$ depth (for details see [7]). Five randomly chosen photographs from each transect were analyzed because additional photographs were determined to not significantly change the mean benthic cover of each functional group. In addition, a two-way ANOVA with site and photoquadrat as factors verified that the number of photoquadrats was sufficient to distinguish differences in percent cover of taxonomic groups between sites.

2.2.2. Reef Fish. Data on numerical abundance and length of reef fish species were collected by a pair of divers along three $25 \mathrm{~m}$ transects, separated by $10 \mathrm{~m}$, on an isobath between 10 $12 \mathrm{~m}$ depth at each site (for details see [7]). Counts were converted into biomass estimates using published lengthweight parameters and summed by major trophic groups [top predators, carnivores, herbivores, and planktivores (see Table S2 in Supporting Information for assignments of fish species to trophic groups)]. As was done with the benthic data, a two-way ANOVA with site and transect as factors verified that the number of transects was sufficient to distinguish differences in biomass of trophic groups between sites.

2.2.3. Fishing. Surveys of fishing activity were conducted during July-August 2007 in the four villages of Kiritimati (Figure 2). The same percentage of surveys was conducted in each village (17\%), except for the smallest village where a higher percentage $(43 \%)$ was sampled to capture the expected variability in household fishing. Households were chosen haphazardly. The head of the household or other person sufficiently knowledgeable of the fishing activities of the household was interviewed after oral consent was obtained. The interviewee was asked to recall catch $(\mathrm{kg})$ by family or species, effort, gear, location, and habitat for all fishing trips conducted over the previous seven days. Each trip was assigned a number, and the interviewee was asked to mark the location of each trip on a map. The fishing data were weighted by the reciprocal of the product of the number of households surveyed in a village and the probability that the household was chosen in order to make population-level estimates of fishing for each village.

2.2.4. Oceanographic Data. Chlorophyll-a was used as a proxy for nutrients because it is a more sensitive indicator of nutrient enrichment than nutrient concentrations themselves $[34,35]$. Data on chlorophyll- $a$ were obtained from MODIS on Aqua at a resolution of 0.04 degrees. Monthly chlorophyll- $a$ data were collected from September 16, 2002 to August 16, 2007. Each site was assigned to the nearest cell, and the average value for the time series was used. When data were missing, the value of the cell was interpolated as the average of the adjacent cells. Chlorophyll- $a$ data from the 24 sites, which were chosen to create the natural factorial design experiment, were tested for differences in chlorophyll$a$ concentrations inside and outside of the upwelling zone using a $t$-test. A categorical variable representing levels of chlorophyll-a (high and low) was then used in two-way fixed effects ANOVAs testing the effects of chlorophyll- $a$ and fishing on benthic taxonomic and fish trophic groups at these 24 sites. Continuous site-specific chlorophyll- $a$ data were used in regression based-analyses of the mechanisms structuring the fish and benthic communities.

Water samples were collected in July-August 2009 and analyzed for chlorophyll- $a$ concentration to verify the patterns observed in the satellite data. A total of 21 surface water samples $(500 \mathrm{~mL})$ were collected in the upwelling zone, and 11 samples were collected outside of the upwelling zone while revisiting the 24 sites used to create the natural factorial design (Figure 1). Water was stored on ice, transported to shore, and filtered. Filters were stored in aluminum foil and frozen at $-20^{\circ} \mathrm{C}$. Upon returning to the lab, pigments were extracted from the filters with a $90 \%$ acetone solution. The extract was centrifuged, and the supernatant was analyzed for chlorophyll- $a$ content using a Turner Designs Model 700 fluorometer. Since analyses could not be done immediately on island, chlorophyll- $a$ concentrations were adjusted for degradation due to storage using the following formula: chl a concentration $=-17.31 * \log \left(\right.$ days stored at $\left.-20^{\circ} \mathrm{C}\right)+95.88$ [36].

\subsection{Data Analysis}

2.3.1. Fishing Data. In total, 145 households were surveyed, which resulted in 248 fishing trips being characterized. The fore-reef habitat accounted for $23 \%$ of fishing trips $(n=$ 57 ), and only these trips were analyzed. The remainder of the fishing trips were in the open ocean (28\%), lagoon $(44 \%)$, or in fish ponds (5\%). Fish catch was binned by $2 \mathrm{~km}$ intervals along the coastline. The distance in either direction from each bin to each village was measured. An exponential function of this distance $(x)$ was fit to the binned fish catch data $(y)\left(y=\beta_{1} * \beta_{2}^{x}\right)\left(R^{2}=0.91, P<\right.$ $.001)$. This function was weighted by the fraction of the fish catch in either direction from each village and then used to estimate fish catch at each ecological survey site using the distance from a village to the site. The total fish catch at a site was the sum of the fish catch from each of these village and direction-specific estimates. Fishing data from the 24 sites, which were chosen to create the natural factorial design experiment, were tested for differences in fish catch near and far from the population center using a $t$-test. As with chlorophyll- $a$, a categorical variable representing levels of fishing (high and low) was then used in two-way fixed effects ANOVAs testing the effects of chlorophyll- $a$ and fishing on benthic taxonomic and fish trophic groups at these 24 sites. Continuous site-specific fish catch data were used in regression-based analyses of the mechanisms structuring the fish and benthic communities. Summary statistics on frequency of gear types and catch composition (percentage of top predator, carnivore, herbivore, and planktivore biomass) were calculated directly from the pooled catch data. Catch composition was compared across areas identified a priori 
as high and low fishing for the natural factorial experiment using MANOVA (Stata v9).

2.3.2. Ecosystem Structure. The differences in mean biomass of fish trophic groups (all log-transformed except for herbivore biomass) and percentage cover of each benthic taxonomic groups were tested using two-way ANOVA with chlorophyll- $a$ and fishing as fixed effects (Stata v9). These data were tested for independence using Moran's I because sites within a given treatment were spatially clustered. There was no evidence of spatial autocorrelation for the nine response variables within any of the four treatments, except for herbivore biomass within the low chlorophyll-a/high fishing treatment (see Table S3 in Supporting Information for tests of independence for response variables within each treatment in the natural factorial experiment and across all sites). However, when herbivore biomass was estimated using ordinary least squares, the residuals were tested for spatial autocorrelation, and no evidence of spatial autocorrelation was found (Moran's $I=-0.04, P=.98$ ), validating the use of the two-way ANOVA. The percentage of variance explained by each fixed factor was calculated using omega squared $\left(\omega^{2}=\left(\mathrm{SS}_{\text {treated }}-\mathrm{df}_{\text {treated }} * \mathrm{MS}_{\text {error }}\right) /\left(\mathrm{SS}_{\text {total }}+\mathrm{MS}_{\text {error }}\right)\right)$ $[37,38]$. Negative values of $\omega^{2}$ were set to zero because their effects were assumed to be negligible [37].

2.3.3. Mechanisms of Ecosystem Change. The full set of 37 sites was used to test mechanisms linking fishing to changes in the biomass of top predators, herbivores, large-bodied fishes $(\geq 20 \mathrm{~cm})$, and small-bodied $(<20 \mathrm{~cm})$ fishes. Two trophic-based fishing mechanisms (trophic cascades and fishing down the food chain) and two size-based fishing mechanisms (size class cascades and fishing down size classes) were tested. Size class cascades refer to patterns in which a low abundance of large fish, due to fishing, is associated with a high abundance of small fish, regardless of the trophic groups. For trophic-based models, I estimated the relationships between (1) fishing and top predators, (2) fishing and herbivores, and (3) top predators and herbivores. For size-class-based models, I estimated the relationship between (1) fishing and large-bodied fishes, (2) fishing and small-bodied fishes, and (3) large-bodied and small-bodied fishes. Linear and log-log models were estimated for the relationship between fishing and the biomass of fish groups. Linear, piecewise, and quadratic models were estimated for the relationship between the biomass of different fish groups. Piecewise models were estimated to test for evidence of fishing down mechanisms and identify points ("cut points") where fishing pressure switches from one fish group to another (see Supplementary Methods). Quadratic models were estimated to test for evidence of mixed control by cascading and fishing down mechanisms.

Prior to model estimation, top predator, herbivore, largebodied fish and small-bodied fish biomass were tested for independence across all sites using Moran's I and failed (see Table S3). Models were then estimated using ordinary least squares. In the case of piecewise models with an unknown cut point, the cut point was first estimated using nonlinear least squares, and then the estimated cut point was used to estimate a piecewise function (see Supplementary Methods). After estimation of each model, the residuals were tested for spatial autocorrelation. If the residuals exhibited spatial autocorrelation, models were estimated using spatial simultaneous autoregressive linear models (R 2.7.0). Akaike's Information Criterion adjusted for sample size $\left(\mathrm{AIC}_{\mathrm{c}}\right)$ was used to assess the relative information content of each model. Normalized Akaike weights $\left(w_{i}=\exp \left(-(1 / 2) \Delta_{i}\right) / \sum_{n=1}^{N} \exp \left(-(1 / 2) \Delta_{n}\right)\right)$ were presented to indicate the probability that the given model $(i)$ was the best model out of the set of $N$ models considered [39]. Monte Carlo permutation tests were used to test the robustness of the best models estimates because there were far fewer observations at sites experiencing high fish catch (R 2.7.0). $P$ values were generated from comparisons of F-statistics associated with ordinary least squares estimates of a model using the observed data and 1,000 random permutations of the data.

The full set of 37 sites was also used to test for mechanisms linking fishing of herbivores and enrichment of nutrients to changes in benthic community structure. Six models representing all combinations of independent and interactive effects of herbivore biomass and chlorophyll- $a$ were estimated for each benthic taxonomic group (coral, CCA, turf, macroalgae) (see Table S6). The four benthic taxonomic groups were tested for independence across all sites using Moran's I and failed (see Table S3). Following the same procedure as was used for models of fishing mechanisms, models were estimated using ordinary least squares, and the residuals were tested for spatial autocorrelation. When there was evidence of spatial autocorrelation, models were estimated using spatial simultaneous autoregressive linear models (R 2.7.0). The $\mathrm{AIC}_{\mathrm{c}}$ and normalized Akaike weights were calculated for each model (see Table S6) to determine which models best explained the patterns of abundance in benthic taxonomic groups (for estimates of best candidate models, see Table S7).

\section{Results}

3.1. Fishing and Chlorophyll-a Conditions. The analysis of chlorophyll- $a$ levels and fishing pressure for the subset of 24 sites validated the factorial experimental design. Fish catch was higher at sites that were $a$ priori assigned to the high fishing "treatment" in the north near the two largest villages $\left(141 \mathrm{~kg} \mathrm{~km}^{-1} \mathrm{wk}^{-1}\right)$, which are inside and outside of the upwelling zone, than away from the villages at sites that were assigned to the low fishing "treatment" $\left(27 \mathrm{~kg} \mathrm{~km}^{-1} \mathrm{wk}^{-1}\right)$ $t_{(22)}=-2.73, P<.01 ;$ Figure 2$)$, supporting the claim that patterns in fishing pressure have been determined exogenously by the population re-settlement program. However, fish catch was not significantly different across sites within the upwelling zone assigned to the high chlorophyll- $a$ "treatment" and sites outside of the upwelling zone assigned to the low chlorophyll- $a$ "treatment" $\left(t_{(22)}=0.12, P=.90\right)$.

Across all sites, fish catch ranged from $445 \mathrm{~kg} \mathrm{~km}^{-1} \mathrm{wk}^{-1}$ to less than $1 \mathrm{~kg} \mathrm{~km}^{-1} \mathrm{wk}^{-1}$. Half of fishing trips used hook 
TABLE 2: Models of effects of fishing on fish trophic group and size-class biomass.

\begin{tabular}{|c|c|c|c|c|}
\hline Dependent & Predictor & $\mathrm{AIC}_{\mathrm{c}}$ & $\Delta \mathrm{AIC}_{\mathrm{c}}{ }^{\dagger}$ & $w_{i}$ \\
\hline \multicolumn{5}{|c|}{ Trophic-based Models } \\
\hline \multirow[t]{2}{*}{$\ln$ (Top Predators) } & $\ln ($ Fish Catch) & 93.67 & 0 & 99.8 \\
\hline & Fish Catch* & 106.05 & 12.38 & 0.2 \\
\hline $\ln$ (Herbivores) & $\ln$ (Fish Catch) & 113.73 & 130.52 & $\ll 0.1$ \\
\hline Herbivores & Fish Catch & -16.79 & 0 & 100.0 \\
\hline \multirow[t]{3}{*}{ Herbivores } & Top Predators* & -0.86 & 12.64 & 0.2 \\
\hline & Quadratic Top Predators & -6.75 & 6.75 & 3.3 \\
\hline & Piecewise Top Predators $^{\ddagger}$ & -12.88 & 0 & 96.5 \\
\hline \multicolumn{5}{|c|}{ Size-based Models } \\
\hline \multirow[t]{2}{*}{$\ln$ (Large-bodied fishes) } & $\ln ($ Fish Catch) & 98.48 & 0 & 82.5 \\
\hline & Fish Catch & 101.58 & 3.1 & 17.5 \\
\hline \multirow[t]{2}{*}{$\ln$ (Small-bodied fishes) } & $\ln (\text { Fish Catch })^{*}$ & 99.93 & 3.92 & 12.3 \\
\hline & Fish Catch & 96.01 & 0 & 87.7 \\
\hline \multirow[t]{3}{*}{$\ln$ (Small-bodied fishes) } & Large-bodied fishes* & 98.35 & 12.28 & 0.2 \\
\hline & Quadratic Large-bodied fishes* & 92.09 & 6.02 & 4.69 \\
\hline & Piecewise Large-bodied fishes ${ }^{\ddagger}$ & 86.07 & 0 & 95.11 \\
\hline
\end{tabular}

${ }^{\dagger}$ Difference in $\mathrm{AIC}_{\mathrm{c}}$ between a given model, $i$, and the model with the minimum $\mathrm{AIC}_{\mathrm{c}}$.

*All predictors are random variables, and models were estimated using ordinary least squares. However, if residuals exhibited spatial autocorrelation, relationships were estimated using spatial simultaneous autoregressive linear models.

${ }^{\ddagger}$ A piecewise regression model is of the form $y=a+b_{1} x+b_{2} x_{c}$, where $a$ is the intercept, $b_{1}$ and $b_{2}$ are slopes, and $x_{c}=x-c(c$ is a cut point) if $x \geq c$ and $x_{c}=0$ if $x<c$.

and line. Gillnets (26\%) and spears (19\%) were the next most common gear. A small percentage of fishermen (5\%) used SCUBA and hand nets to collect fish for the aquarium trade. Top predators $(37 \%)$ and herbivores (36\%) comprised the largest percentage of the total catch by biomass. Carnivores $(20 \%)$ were the next largest, and planktivores (7\%) were a small percentage of the total catch. Catch composition (percentage of biomass by trophic group) was not different in areas with high and low fish catch $\left(F_{(4,76)}=1.18, P=.32\right)$.

The twelve sites along the northwestern coastline in the upwelling zone that were assigned to the high chlorophyll$a$ "treatment" had a $18.6 \%$ (95\% CI: $17.7 \%-18.8 \%)$ higher mean chlorophyll- $a$ concentration $\left(0.221 \mathrm{mg} \mathrm{m}^{-3}\right)$, as observed monthly by MODIS on Aqua between 2002 and 2007 than the twelve sites along the northeastern coastline, which are outside of the upwelling zone and assigned to the low chlorophyll- $a$ "treatment" $\left(0.180 \mathrm{mg} \mathrm{m}^{-3}\right)\left(t_{(22)}=\right.$ $-6.14, P<.0001$; Figure 2). In situ chlorophyll- $a$ concentrations measured in 2009 also supported this pattern $\left(t_{(30)}=-2.16, P<.05\right)$. When all sites were considered, a $41.2 \%$ (95\% CI: $37.6 \%-44.4 \%$ ) difference in chlorophyll- $a$ concentration was observed from the highest to the lowest chlorophyll- $a$ site. Satellite-derived chlorophyll- $a$ levels were not, however, significantly different across areas within the high and low fishing "treatments" $\left(t_{(22)}=-1.35, P=.19\right)$. Although the lagoon entrance and one of the two largest villages are in the upwelling zone, current and isotope data suggest that the nutrient patterns are determined exogenously by patterns of upwelling. Interpolation of surface currents from ACDP vector data shows an inflow of water to the lagoon (see Figure S1). Moreover, the lagoon waters are largely oligotrophic given the limited land runoff. In addition, Dinsdale et al. [32] found no evidence of human waste water in the nitrogen isotope signature of particulate organic matter in the upwelling zone.

3.2. Ecosystem Structure. Fishing had the largest effect on and explained most of the variance in the biomass of the upper trophic levels of the fish community (see Table S4 in Supporting Information). Top predator biomass was $75 \%$ higher at sites with low fish catch $\left(0.78 \mathrm{mTha}^{-1}\right)$ as compared to sites with high fish catch $\left(0.18 \mathrm{mTha}^{-1}\right)$ $\left(F_{(1,20)}=8.37, P<.01\right)$. Carnivore biomass was $63 \%$ lower at sites with high fish catch $\left(F_{(1,20)}=7.80, P<.05\right)$. In contrast, planktivore biomass was only $36 \%$ lower at these sites $\left(F_{(1,20)}=4.54, P<.05\right)$. Herbivore biomass showed no change over the range of fish catch captured in the factorial experimental design $\left(F_{(1,20)}=1.22, P=.28\right)$, although parrotfish biomass was marginally lower at sites with high fish catch $\left(F_{(1,20)}=2.45, P=.13\right)$.

Chlorophyll- $a$ mainly affected the lower trophic levels of the benthic community (see Table S5 in Supporting Information for results of two-way ANOVA comparing effects of fishing and chlorophyll- $a$ on benthic taxonomic group percent cover). Percent cover of both turf $\left(F_{(1,20)}=\right.$ $10.24, P<.01)$ and macroalgae $\left(F_{(1,20)}=11.06, P<.01\right)$ was higher at sites with high chlorophyll- $a$, whereas CCA cover was lower $\left(F_{(1,20)}=17.56, P<.001\right)$. Macroalgal cover was also higher at sites with high fish catch $\left(F_{(1,20)}=4.86, P<\right.$ $.05)$. Although macroalgal cover was affected by fishing and chlorophyll- $a$, coral cover was not affected by either fishing $\left(F_{(1,20)}=0.00, P=.98\right)$ or chlorophyll- $a\left(F_{(1,20)}=1.75, P=\right.$ $.20)$. The only fish group affected by chlorophyll- $a$ was the planktivores $\left(F_{(1,20)}=9.19, P<.01\right)$. Planktivore biomass 


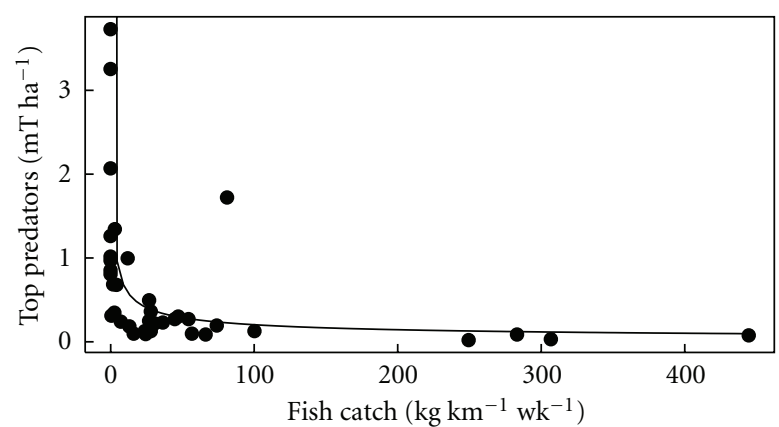

(a)

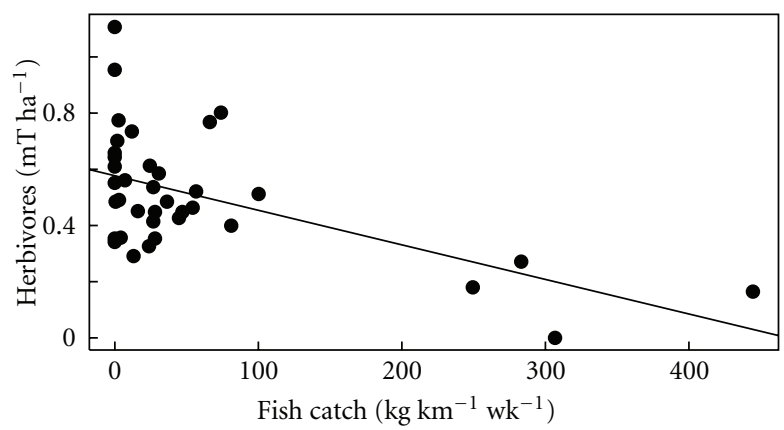

(c)

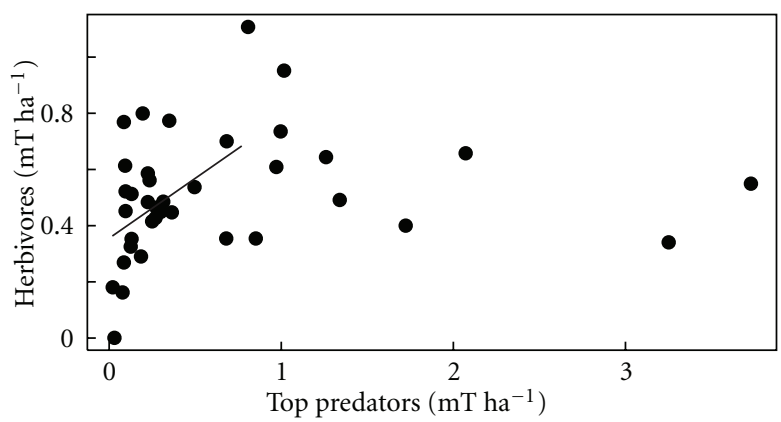

(e)

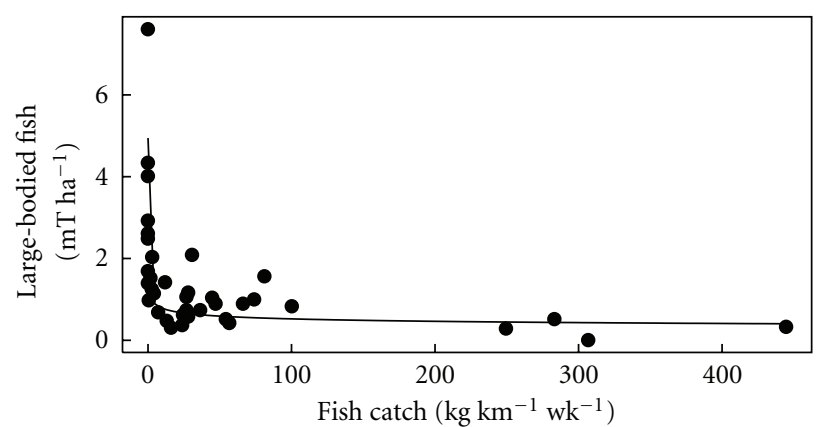

(b)

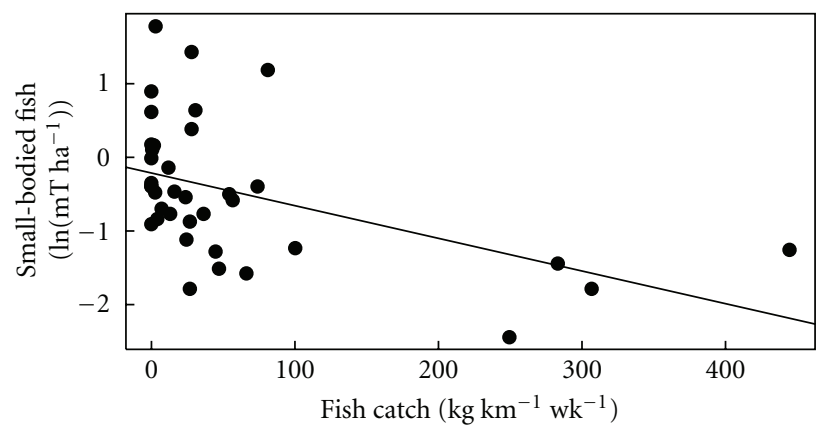

(d)

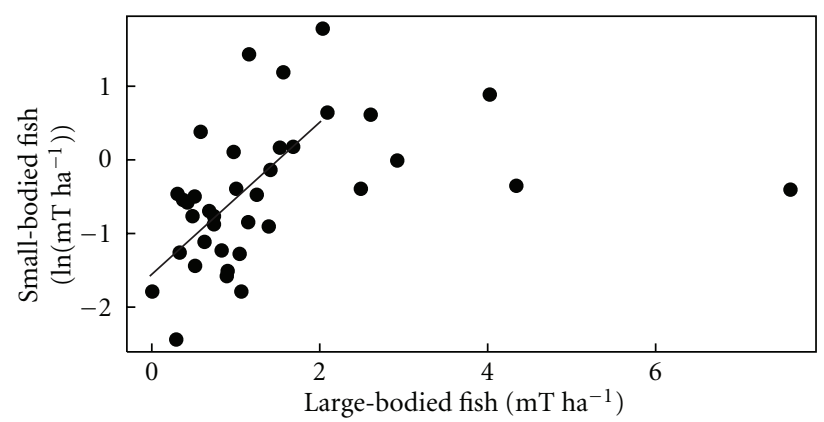

(f)

FIgURE 3: The effects of fishing on top predators, herbivores, large- and small-bodied fish biomass. Fishing resulted in exponential declines in top predator $\left((\mathrm{a}) R^{2}=0.58, P<.0001\right.$; permutation test: $\left.P<.0001\right)$ and large-bodied fishes $\left((\mathrm{b}) R^{2}=0.43, P<.0001\right.$, permutation test: $P<.0001)$ biomass. Herbivores $\left((\mathrm{c}) R^{2}=0.30, P<.001\right.$, permutation test: $\left.P<.0001\right)$ and small-bodied fishes $\left((\mathrm{d}) R^{2}=0.22, P<.01\right.$, permutation test: $P<.01)$ biomass declined linearly with fish catch. Herbivore biomass only declined when top predator biomass was less than $0.81 \mathrm{mT} / \mathrm{ha}(95 \% \mathrm{CI}: 0.16,1.44)\left((\mathrm{e}) R^{2}=0.24, P<.01\right.$, permutation test: $\left.P<.05\right)$. Small-bodied fish biomass only declined when large-bodied fish biomass was less than $2.04 \mathrm{mT} / \mathrm{ha}(95 \% \mathrm{CI}: 1.16,2.90)\left((\mathrm{f}) R^{2}=0.41, P<.001\right.$, permutation test: $\left.P<.0001\right)$.

was higher at low chlorophyll- $a$ sites, outside of the upwelling zone. Planktivores outside of the upwelling zone were mostly large-bodied Fusiliers as compared to small-bodied Anthias and Chromis inside the upwelling zone.

3.3. Mechanisms of Ecosystem Change. The full set of 37 sites was used for tests of mechanisms linking (1) fishing to changes in top predators, herbivores, large-bodied fishes, and small-bodied fishes and (2) fishing of herbivores and enrichment of nutrients to changes in benthic community structure. Fishing resulted in an exponential decline of top predators from $3.73 \mathrm{mT} \mathrm{ha}^{-1}$ (73\% of total biomass) at the least fished site to $0.02 \mathrm{mT} / \mathrm{ha}$ ( $6 \%$ of total biomass) at the most fished site (Table 2, Figure 3(a)). Large-bodied fishes showed a similar trend from $7.61 \mathrm{mT} \mathrm{ha}^{-1}$ (92\% of total biomass) to $<0.01 \mathrm{mT} \mathrm{ha}^{-1}$ ( $4 \%$ of total biomass) (Table 2, Figure 3(b)). Herbivore and small-bodied fishes declined less dramatically with fish catch (Table 2, Figures 3(c) and $3(\mathrm{~d}))$; however, both were highly variable at sites with low fish catch. This pattern may be explained by the apparently bimodal relationships between trophic groups and between size classes. When top predator biomass is high (cut point: $\geq 0.81 \mathrm{mT} /$ ha $(95 \% \mathrm{CI}: 0.16,1.44)$ ), corresponding to low fish catch, herbivore biomass was unrelated to top predator biomass but then declined when top predator biomass was low $(<0.81 \mathrm{mT} / \mathrm{ha})$, supporting the fishing down the food chain hypothesis (Table 2, Figure 3(e)). Small-bodied fishes biomass showed the same pattern, with biomass 


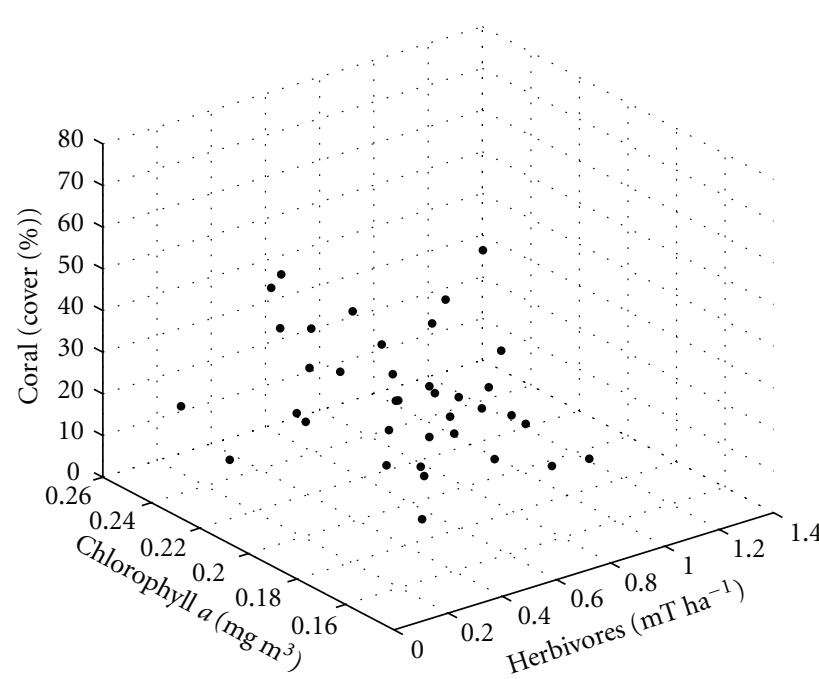

(a)

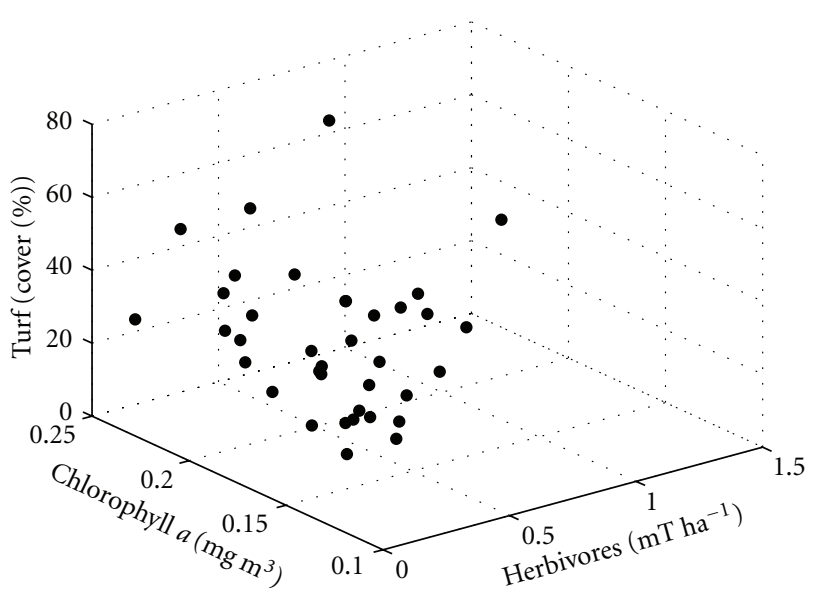

(c)

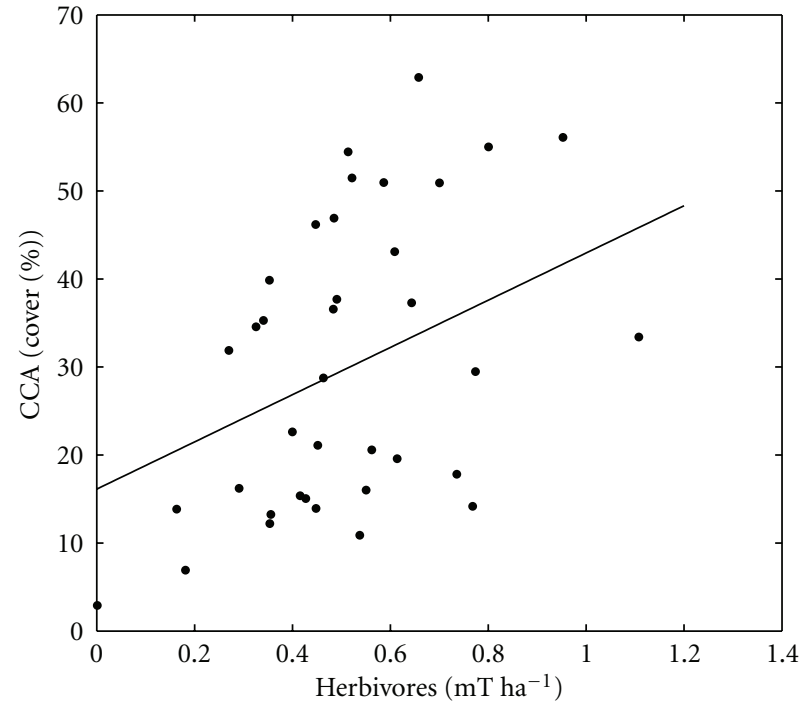

(b)

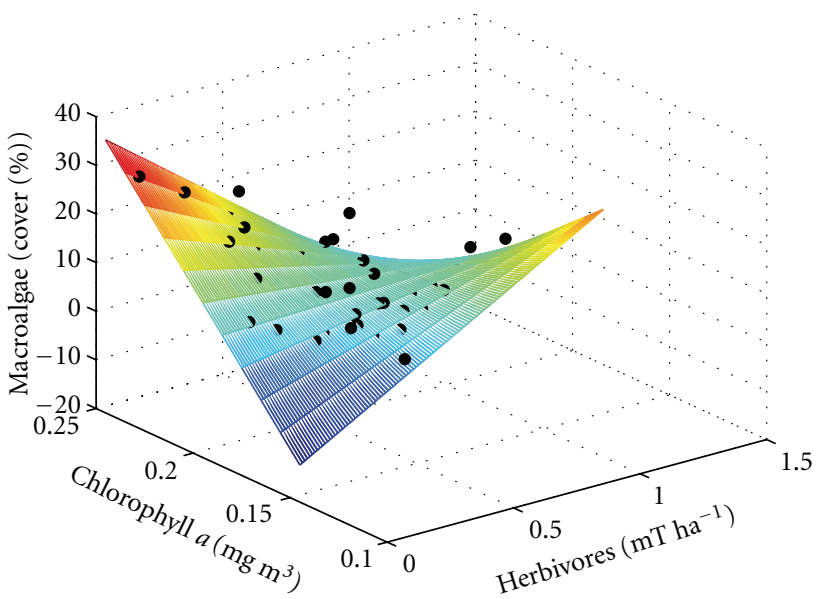

(d)

FIGURE 4: The effect of herbivores and chlorophyll- $a$ on benthic functional groups. (a) Coral was not significantly affected by herbivores, chlorophyll- $a$, or their interaction, (b) CCA and fitted values (black line) as a function of herbivore biomass $(P<.01)\left(\right.$ pseudo $R^{2}=0.59$, $P<.05)$, (c) turf was not significantly affected by herbivores, chlorophyll- $a$, or their interaction, and (d) macroalgae and fitted values (rainbow mesh) predicted by herbivores $(P<.01)$, nutrients $(P<.001)$, and an interactive term $(P<.01)\left(R^{2}=0.56, P<.0001\right)$. See Tables S6 and S7 in Supporting Information for model selection and detailed statistics.

declining only when large-bodied fish biomass was low (cut point: $<2.04 \mathrm{mT} / \mathrm{ha}$ (95\% CI: 1.16, 2.90)), supporting the fishing down size classes hypothesis (Table 2, Figure 3(f)). Permutation tests verified the robustness of these model estimates to the low number of sites sampled under low fishing conditions.

No single model carried the majority of the weight (i.e., $\left.w_{i}>0.50\right)$ in explaining the abundance of coral, CCA, and turf (see Table S6 in Supporting Information for results of selection of best models of the effect of herbivores and chlorophyll- $a$ on the percent cover of benthic taxonomic groups). Coral cover was best explained $\left(w_{i}=0.25\right)$ by the additive effects of herbivore biomass and chlorophylla levels with all other models having weights equal or less than 0.20; however, these individual effects were not significant (Figure 4(a), Table S6, see Table S7 in Supporting
Information for detailed statistics of model estimates of the effect of herbivores, chlorophyll- $a$ and/or their interaction on benthic taxonomic groups from the best candidate models). Models with herbivore biomass alone $\left(w_{i}=0.29\right)$ and herbivore biomass and the interaction between herbivore biomass and chlorophyll- $a\left(w_{i}=0.28\right)$ were almost equally likely to provide the best estimates of CCA cover (see Tables S6 and S7). These models provide evidence that increases in herbivore biomass should be associated with increases in CCA cover but that the magnitude of this effect should decrease with increasing chlorophyll- $a$ levels, although this interactive effect is only significant at a $90 \%$ confidence level (Figure 4(b), see Table S7). Models with herbivore biomass alone $\left(w_{i}=0.24\right)$ and herbivore biomass and the interaction between herbivore biomass and chlorophyll- $a$ $\left(w_{i}=0.26\right)$ were also almost equally likely to provide the 


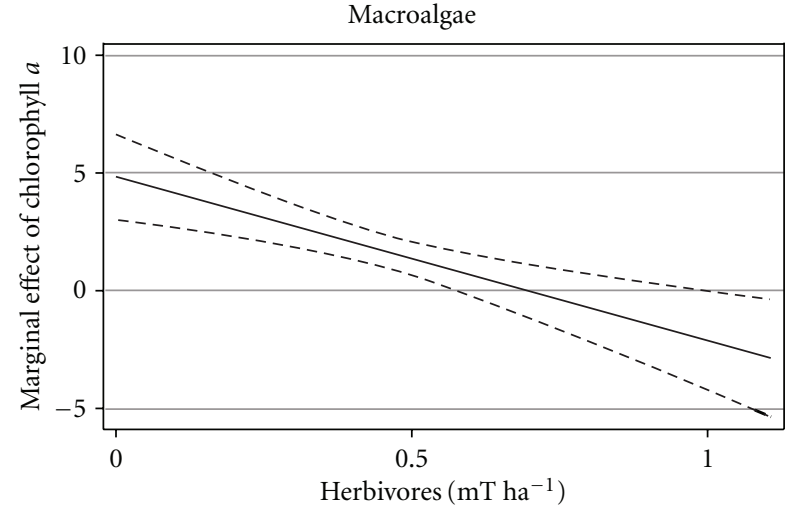

(a)

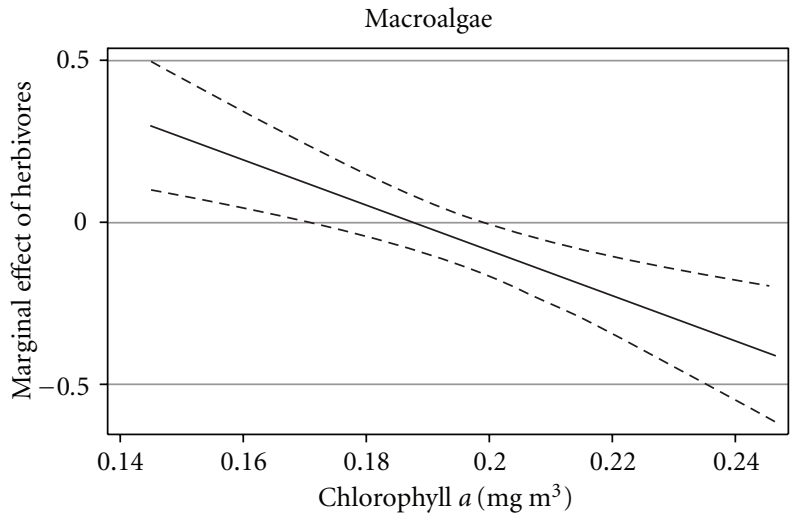

(b)

FIGURE 5: The marginal effects of herbivores and chlorophyll- $a$ on macroalgae. (a) The marginal effect of chlorophyll- $a$ on macroalgae as a function of herbivore biomass and (b) the marginal effect of herbivores on macroalgae as a function of chlorophyll- $a$. Marginal effects were estimated from the best fit model of macroalgae to herbivores, chlorophyll- $a$, and their interaction (see Tables S6 and S7). Dotted lines are $95 \%$ confidence intervals.

best estimates of turf cover; however, the effects were not significant (Figure 4(c), see Tables S6 and S7).

A model of macroalgal cover including the predictor variables herbivores, chlorophyll- $a$, and their interaction, had a very high level of support $\left(w_{i}=0.98\right)$. Herbivores and chlorophyll- $a$ had significant independent and interactive effects on macroalgal cover (Figure 4(d), see Tables S6 and S7). Increases in herbivore biomass were estimated to result in decreases in macroalgal cover, and this effect was enhanced with increasing chlorophyll-a (Figure 5(a)). Macroalgal cover was estimated to increase with increasing chlorophyll- $a$; however, increasing herbivore biomass reduced this effect (Figure 5(b)).

\section{Discussion}

The results of this large-scale natural experiment support those found at smaller scales, namely, that herbivores and nutrients control the balance between macroalgae and turf algae and reef-builders [14]. However, this study expands on previous research to show that (1) fishing primarily affects the fish community while nutrients primarily affect the benthic community, (2) fishing down the food chain or size classes are the best supported mechanisms by which fishing indirectly affects the benthos, and (3) herbivores and nutrients have unexpected interactive effects on macroalgal cover at large spatial scales. The first finding increases our understanding of the independent and interactive effects of nutrients and fishing on the benthic and fish community by including additional taxa and measuring fishing directly, while the other findings have important implications for management.

Fishing significantly decreased the biomass of all fish functional groups, when sites from the full fishing gradient were considered, and had the greatest effect on the upper trophic levels and large-bodied fishes. About half of fishing trips observed used hook and line, which selects for larger predators or carnivores. This was evidenced by the fact that almostly $40 \%$ of the catch was comprised of top predators and $20 \%$ was carnivores. It is not surprising then that fishing had a strong effect on both top predator and large-bodied fish biomass. However, the exponentially lower level of these groups at sites with high fishing is probably due also to their extreme vulnerability to fishing since they tend to have slow growth and late maturation [23].

Herbivore and small-bodied fish biomass showed less dramatic differences between sites with different levels of fishing. Herbivore biomass was highly variable and not significantly affected by fishing when only the 24 sites included in the natural factorial design experiment, which do not include the mostly lightly fished sites, were evaluated. Gillnets, which are unselective and can capture herbivores and small fish, were used in about a quarter of all fishing trips. Spears, which are highly selective, were used in $14 \%$ of all fishing trips to catch larger herbivores, among other fish. Although almost $40 \%$ of the total catch was herbivores, the diversity of life histories of herbivores may ameliorate the effects on the entire functional group. In addition, there may have been insufficient statistical power to detect differences in herbivore biomass in the natural factorial experimental design, given the high variability of herbivore biomass at these sites. It is also possible that the variability in herbivore biomass at these sites reflects the higher variability in benthic community structure and is less related to fishing pressure.

There was no evidence that fishing top predators or largebodied fishes was associated with higher levels of herbivores or small-bodied fishes, respectively. This is consistent with the general finding that trophic cascades are not widespread on coral reefs [22]. However, trophic cascades has been observed involving invertebrates, such as sea urchins and crown-of-thorns [40-43]. These invertebrates were virtually absent from reefs on Kiritimati; however, in more recent visits a high abundance of urchins have been observed at the most heavily fished sites. Evidence of an increase in the smallest size classes of fish have been observed on Fijian reefs [17]. However, this was not observed on Kiritimati possibly because the mixed gear fishery and flexibility of the local diet allow fishermen to switch to targeting herbivores 
and small-bodied fishes at sites where top predators and large-bodied fishes are not abundant. Together these findings help inform the debate over whether restoring top predator populations in marine reserves may have direct negative impacts on herbivore populations and indirect negative impacts on corals through reduced herbivory [18]. Marine reserves are unlikely to have negative indirect effects on corals if trophic cascades are uncommon on coral reef and spillover of predators from marine reserves may even help effectively protect herbivores outside the reserves if top predators are fished preferentially.

Herbivore biomass and nutrients (proxied by chlorophyll-a) were important predictors of benthic community structure. Coral, CCA, and turf algal cover exhibited mixed control, as evidenced by the fact that no single model of herbivore, nutrients, and their interaction had the majority of support (measured by $\mathrm{AIC}_{\mathrm{c}}$ weights). In contrast, there was overwhelming support for a model including main and interactive effects of herbivores and nutrients as the best predictor of macroalgal cover. None of the predictors in the best supported models of coral and turf algal cover were significant at a $95 \%$ confidence level, while all predictors in the best candidate models for CCA and macroalgal cover were significant at this level. The intermediate response times of CCA and macroalgae in comparison to the very fast and very slow response times of turf algae and coral, respectively, may explain this difference in the significance of predictor variables. Turf may grow rapidly after being grazed making the effects of herbivores difficult to observe. Corals grow slowly and may maintain the same size over long time scales despite changes in nutrients and herbivores, making percent cover a less sensitive metric. Despite the lack of significant effects of herbivores and nutrients on corals, the observed decline in CCA and increase in macroalgae in response to fishing herbivores and nutrient enrichment suggest that future declines in corals may occur due to decreased survival of recruits [32]. These results also support the hypothesis that differences in the levels of reef-builder cover found for the leeward sides of the northern Line Islands must be due at least in part to differences in fishing pressure and cannot be attributed to oceanographic effects alone [7].

In contrast to theoretical predictions, a significant interactive effect of herbivores and nutrients on macroalgae was found at a large spatial scale (interactive effects were only significant at a $90 \%$ confidence level for turf algae) when all sites were analyzed using regression based methods. The natural factorial experiment results that were based on a subset of sites, however, did not find support for interactive effects of fishing and nutrients on macroalgae. This may be due to insufficient power, the insignificant effect of fishing on herbivores at these sites or that reductions in herbivores due to fishing, not fishing in general, affect macroalgae. Similar to small-scale manipulative experimental results, macroalgal cover was higher when nutrients were high and herbivores were low but nutrients had less of an effect on macroalgae when herbivores were high $[14,21]$. This suggests that herbivores are able to track resources even at larger spatial scales and/or predators have a limited ability to control herbivores. In another large-scale natural experiment, Russ and McCook [44] found evidence that herbivores could control macroalgal growth following a cyclone that elevated nutrient inputs. However, a cyclone only results in a short pulse of nutrients while island-wake upwelling on Kiritimati results in persistently higher nutrients. In addition, the limited evidence for trophic cascades in this study and others supports the claim that predators do not control herbivore abundance. However, unlike small-scale experimental results, herbivores had less of an effect on macroalgae when nutrients were low. One possible explanation for this trend is that macroalgae are less susceptible to herbivory at lower nutrient levels due to plasticity within a species or changes in community composition [26]. In fact, Peyssonnelia spp. and Lobophora sp., which have been shown to be highly resistant to herbivory, were more abundant at sites with lower chlorophyll-a concentrations $[45,46]$. This result may not be commonly reported because the time scale of manipulative experiments may be too short to observe shifts in species composition or algal defenses [26]. To resolve these issues, experimental designs that extend the spatial and temporal scale of these impacts are needed $[21,26]$.

This study provides insight into how the results of smallscale experiments apply to ecosystem-based management because it was conducted at a large scale and measured effects on the fish and benthic communities. It also improves upon studies that have used natural gradients in nutrients $[13,47]$ or fishing $[4,5,7]$ by taking advantage of orthogonal gradients in both factors, measuring fishing directly through the use of household surveys rather than using human population as a proxy, and using spatial simultaneous autoregressive linear models to address issues of spatial autocorrelation, when necessary.

This study, however, is still limited because it examined a relatively small number of reefs on a single island in a single season, it did not experimentally manipulate the factors, and nutrient enrichment was natural and relatively low compared to polluted reefs (reefs polluted by sewage in Kaneohe, Hawaii had chlorophyll- $a$ levels up to $0.68 \mathrm{mg} \mathrm{m}^{-3}$ [48]). Ideally the study would have examined multiple sites with all combinations of high and low fishing and nutrient pollution or manipulated these factors over 10s of kilometers. However, I am unaware of sites with these conditions, and large-scale manipulations may be impractical or unethical. Despite the small number of sites surveyed, especially in low fishing conditions, permutation tests verified the robustness of these results. In addition, fishermen noted during household surveys that fisheries on Kiritimati have limited seasonality, suggesting that a survey in a single season may be a good representation of fishing activities. By taking advantage of a unique situation in which fishing and nutrients can be argued to be determined exogenously by oceanography and government policy, some inference can be made about the causal role of fishing and nutrients in ecosystem patterns at large spatial scales. However, other factors, such as wave exposure, light, and temperature, could not be controlled across "treatments." Data on mean wave direction from the Christmas Island Buoy shows that the island is exposed to both north and 
south swells with similar frequency, therefore, it cannot be concluded that there are consistent differences in wave exposure at sites with different levels of fishing or nutrients [49] (Figure S3). Given that nutrient concentrations vary due to upwelling, light and temperature would be expected to be confounded with nutrients. Although the role of light and temperature cannot be rejected with the data presented here, a study of upwelling, caused by internal tidal bores, on Florida coral reefs showed increased $\mathrm{N}$ and $\delta^{15} \mathrm{~N}$ and decreased $\mathrm{C}: \mathrm{N}$ ratio in benthic macroalgae across a gradient of increased exposure to upwelling, which provides evidence for a mechanistic linkage between nutrients and algal growth despite evident differences in temperature and light [47].

Natural and manipulative experiments have their limitations, but results from both are needed especially for the development and evaluation of ecosystem-based management strategies [50]. Future research should develop a set of ecosystem-based management scenarios by conducting manipulative experiments at reef sites that represent the range of nutrient and fishing conditions and then use economic valuation methods to estimate the costs and benefits of reducing fishing and/or nutrients under different background conditions.

The common coincidence of fishing and nutrient enrichment, either due to better weather conditions for fishing in the lee of islands where island-wake upwelling occurs or the proximity of fishing grounds to sources of pollution, suggests that coral reefs in preferred fishing areas may be more sensitive to overfishing. Two management strategies are suggested by this study, which warrant further investigation. In the case of island-wake upwelling, reserves or spatial fish catch limits could be used to shift fishing pressure away from areas of high nutrients in order to reduce the risk of losing reef-builders. Similar policies could be used in the case of nutrient pollution; however, the costs of fisheries regulations should be weighed against the benefits of reducing other economic activities, which cause nutrient pollution. Fishing regulations should specifically aim to shift fishing effort away from herbivores and toward invertivores or planktivores, which may not have negative indirect effects on corals. Although managing both fishing and nutrients is important, protecting herbivore populations may result in greater relative benefits since herbivores can control macroalgae in the presence of nutrient enrichment, are even more effective grazers of macroalgae at high nutrient levels, and independently promote higher CCA cover.

\section{Acknowledgments}

Thanks are due to M. Donovan, R. Walsh, L. Dinsdale, R. Edwards, T. McDole, and M. Vermeij and the staff of Dive Kiribati and the Kiritimati Fisheries Division for help in the field. Thanks are due to S. Sandin for providing the author with a database with a regional fish list, length-weight parameters, and trophic assignments. Thanks are due to J. Smith for training the author on photoquad analysis with Photogrid. Thanks are due to G. Jaroslow for providing insights into the local oceanography at Kiritimati. Thanks to J. Jackson, N. Knowlton, J. Leichter, L. McClenachan, J. Smith, N. Dulvy, H. Leslie, and two anonymous reviewers for reviewing the paper.

\section{References}

[1] S. Jennings, E. M. Grandcourt, and N. V. C. Polunin, "The effects of fishing on the diversity, biomass and trophic structure of Seychelles' reef fish communities," Coral Reefs, vol. 14, no. 4, pp. 225-235, 1995.

[2] A. M. Friedlander and E. E. DeMartini, "Contrasts in density, size, and biomass of reef fishes between the northwestern and the main Hawaiian islands: the effects of fishing down apex predators," Marine Ecology Progress Series, vol. 230, pp. 253264, 2002.

[3] J. M. Pandolfi, R. H. Bradbury, E. Sala et al., "Global trajectories of the long-term decline of coral reef ecosystems," Science, vol. 301, no. 5635, pp. 955-958, 2003.

[4] N. K. Dulvy, R. P. Freckleton, and N. V. C. Polunin, "Coral reef cascades and the indirect effects of predator removal by exploitation," Ecology Letters, vol. 7, no. 5, pp. 410-416, 2004.

[5] M. J. H. Newman, G. A. Paredes, E. Sala, and J. B. C. Jackson, "Structure of Caribbean coral reef communities across a large gradient of fish biomass," Ecology Letters, vol. 9, no. 11, pp. 1216-1227, 2006.

[6] K. Newton, I. M. Côté, G. M. Pilling, S. Jennings, and N. K. Dulvy, "Current and future sustainability of island coral reef fisheries," Current Biology, vol. 17, no. 7, pp. 655-658, 2007.

[7] S. A. Sandin, J. E. Smith, E. E. DeMartini et al., "Baselines and degradation of coral reefs in the Northern Line Islands," PLoS ONE, vol. 3, no. 2, article no. e1548, 2008.

[8] B. E. Lapointe, "Nutrient thresholds for bottom-up control of macroalgal blooms on coral reefs in Jamaica and southeast Florida," Limnology and Oceanography, vol. 42, no. 5, pp. 1119-1131, 1998.

[9] J. F. Bruno, L. E. Petes, C. D. Harvell, and A. Hettinger, "Nutrient enrichment can increase the severity of coral diseases," Ecology Letters, vol. 6, no. 12, pp. 1056-1061, 2003.

[10] P. W. Sammarco, "Echinoid grazing as a structuring force in coral communities: whole reef manipulations," Journal of Experimental Marine Biology and Ecology, vol. 61, no. 1, pp. 31-55, 1982.

[11] L. J. McCook, "Macroalgae, nutrients and phase shifts on coral reefs: scientific issues and management consequences for the Great Barrier Reef," Coral Reefs, vol. 18, no. 4, pp. 357-367, 1999.

[12] J. E. Smith, C. M. Smith, and C. L. Hunter, "An experimental analysis of the effects of herbivory and nutrient enrichment on benthic community dynamics on a Hawaiian reef," Coral Reefs, vol. 19, no. 4, pp. 332-342, 2001.

[13] B. E. Lapointe, P. J. Barile, C. S. Yentsch, M. M. Littler, D. S. Littler, and B. Kakuk, "The relative importance of nutrient enrichment and herbivory on macroalgal communities near Norman's Pond Cay, Exumas Cays, Bahamas: a "natural" enrichment experiment," Journal of Experimental Marine Biology and Ecology, vol. 298, no. 2, pp. 275-301, 2004.

[14] D. E. Burkepile and M. E. Hay, "Herbivore vs. nutrient control of marine primary producers: context-dependent effects," Ecology, vol. 87, no. 12, pp. 3128-3139, 2006.

[15] A.-S. Crépin, "Using fast and slow processes to manage resources with thresholds," Environmental and Resource Economics, vol. 36, no. 2, pp. 191-213, 2007. 
[16] C. Stevenson, L. S. Katz, F. Micheli et al., "High apex predator biomass on remote Pacific islands," Coral Reefs, vol. 26, no. 1, pp. 47-51, 2007.

[17] N. K. Dulvy, N. V. C. Polunin, A. C. Mill, and N. A. J. Graham, "Size structural change in lightly exploited coral reef fish communities: evidence for weak indirect effects," Canadian Journal of Fisheries and Aquatic Sciences, vol. 61, no. 3, pp. 466475, 2004.

[18] P. J. Mumby, C. P. Dahlgren, A. R. Harborne et al., "Fishing, trophic cascades, and the process of grazing on coral reefs," Science, vol. 311, no. 5757, pp. 98-101, 2006.

[19] T. R. McClanahan, M. Nugues, and S. Mwachireya, "Fish and sea urchin herbivory and competition in Kenyan coral reef lagoons: the role of reef management," Journal of Experimental Marine Biology and Ecology, vol. 184, no. 2, pp. 237-254, 1994.

[20] T. R. McClanahan, "Primary succession of coral-reef algae: differing patterns on fished versus unfished reefs," Journal of Experimental Marine Biology and Ecology, vol. 218, no. 1, pp. 77-102, 1997.

[21] J. E. Smith, C. L. Hunter, and C. M. Smith, "The effects of top-down versus bottom-up control on benthic coral reef community structure," Oecologia, vol. 163, no. 2, pp. 497-507, 2010.

[22] S. A. Sandin, S. M. Walsh, and J. B. C. Jackson, "Prey release, trophic cascades, and phase shifts in tropical nearshore marine ecosystems," in Trophic Cascades: Predators, Prey, and the Changing Dynamics of Nature, J. Estes and J. Terborgh, Eds., pp. 71-90, Island Press, 2010.

[23] S. Jennings, S. P. R. Greenstreet, and J. D. Reynolds, "Structural change in an exploited fish community: a consequence of differential fishing effects on species with contrasting life histories," Journal of Animal Ecology, vol. 68, no. 3, pp. 617627, 1999.

[24] D. Pauly, V. Christensen, J. Dalsgaard, R. Froese, and F. Torres Jr., "Fishing down marine food webs," Science, vol. 279, no. 5352, pp. 860-863, 1998.

[25] J. E. Cinner, T. R. McClanahan, T. M. Daw et al., "Linking social and ecological systems to sustain coral reef fisheries," Current Biology, vol. 19, no. 3, pp. 206-212, 2009.

[26] D. S. Gruner, J. E. Smith, E. W. Seabloom et al., "A crosssystem synthesis of consumer and nutrient resource control on producer biomass," Ecology Letters, vol. 11, no. 7, pp. 740755,2008

[27] M. D. Hunter and P. W. Price, "Playing chutes and ladders: heterogeneity and the relative roles of bottom-up and topdown forces in natural communities," Ecology, vol. 73, no. 3, pp. 724-732, 1992.

[28] G. Englund, "Importance of spatial scale and prey movements in predator caging experiments," Ecology, vol. 78, no. 8, pp. 2316-2325, 1997.

[29] N. L. Poff and K. Nelson-Baker, "Habitat heterogeneity and algal-grazer interactions in streams: explorations with a spatially explicit model," Journal of the North American Benthological Society, vol. 16, no. 1, pp. 263-276, 1997.

[30] Asian Development Bank, "Monetization in an atoll society:managing economic and social change," Report 111002, Asian Development Bank, Manila, Philippines, 2002.

[31] C. D. Woodroffe and R. F. McLean, "Pleistocene morphology and holocene emergence of Christmas (Kiritimati) Island, Pacific Ocean," Coral Reefs, vol. 17, no. 3, pp. 235-248, 1998.

[32] E. A. Dinsdale, O. Pantos, S. Smriga et al., "Microbial ecology of four coral atolls in the Northern Line Islands," PLoS ONE, vol. 3, no. 2, article no. e1584, 2008.
[33] K. L. McLeod and H. M. Leslie, "Why ecosystem-based management?" in Ecosystem-Based Management for the Oceans, K. McLeod and H. Leslie, Eds., pp. 3-12, Island Press, Washington, DC, USA, 2009.

[34] E. A. Laws and D. Redalje, "Effects of sewage enrichment on the phytoplankton population of a subtropical estuary," Pacific Science, vol. 33, pp. 129-144, 1979.

[35] P. R. F. Bell, "Eutrophication and coral reefs-some examples in the Great Barrier Reef lagoon," Water Research, vol. 26, no. 5, pp. 553-568, 1992.

[36] R. F. C. Mantoura, S. W. Wright, S. W. Jeffrey, R. G. Barlow, and D. E. Cummings, "Filtration and storage of pigments from microalgae," in Phytoplankton pigments in oceanography, S. W. Jeffrey, R. F. C. Mantoura, and S. W. Wright, Eds., pp. 283-306, UNESCO, Paris, France, 1997.

[37] M. H. Graham and M. S. Edwards, "Statistical significance versus fit: estimating the importance of individual factors in ecological analysis of variance," Oikos, vol. 93, no. 3, pp. 505$513,2001$.

[38] S. Olejnik and J. Algina, "Generalized eta and omega squared statistics: measures of effect size for some common research designs," Psychological Methods, vol. 8, no. 4, pp. 434-447, 2003.

[39] K. P. Burnham and D. R. Anderson, Model Selection and Multimodel Inference: A Practical Information-Theoretic Approach, Springer, New York, NY, USA, 2nd edition, 2002.

[40] T. R. McClanahan and S. H. Shafir, "Causes and consequences of sea urchin abundance and diversity in Kenyan coral reef lagoons," Oecologia, vol. 83, no. 3, pp. 362-370, 1990.

[41] T. R. McClanahan and N. A. Muthiga, "Changes in Kenyan coral reef community structure and function due to exploitation," Hydrobiologia, vol. 166, no. 3, pp. 269-276, 1988.

[42] T. R. McClanahan, "Recovery of a coral reef keystone predator, Balistapus undulatus, in East African marine parks," Biological Conservation, vol. 94, no. 2, pp. 191-198, 2000.

[43] N. K. Dulvy, R. P. Freckleton, and N. V. C. Polunin, "Coral reef cascades and the indirect effects of predator removal by exploitation," Ecology Letters, vol. 7, no. 5, pp. 410-416, 2004.

[44] G. R. Russ and L. J. McCook, "Potential effects of a cyclone on benthic algal production and yield to grazers on coral reefs across the central Great Barrier Reef," Journal of Experimental Marine Biology and Ecology, vol. 235, no. 2, pp. 237-254, 1999.

[45] M. M. Littler, P. R. Taylor, and D. S. Littler, "Algal resistance to herbivory on a Caribbean barrier reef," Coral Reefs, vol. 2, no. 2, pp. 111-118, 1983.

[46] L. D. Coen and C. E. Tanner, "Morphological variation and differential susceptibility to herbivory in the tropical brown alga Lobophora variegata," Marine Ecology Progress Series, vol. 54, pp. 287-298, 1989.

[47] J. J. Leichter, H. L. Stewart, and S. L. Miller, "Episodic nutrient transport to Florida coral reefs," Limnology and Oceanography, vol. 48, no. 4, pp. 1394-1407, 2003.

[48] S. V. Smith, W. J. Kimmerer, E. A. Laws, R. E. Brock, and T. W. Walsh, "Kaneohe Bay sewage diversion experiment: perspectives on ecosystem responses to nutritional perturbation," Pacific Science, vol. 35, no. 4, pp. 279-395, 1981.

[49] NOAA, "Station 51028-Christmas Island," National Data Buoy Center, 2010, http://www.ndbc.noaa.gov/station_page .php?station $=51028$.

[50] F. Guichard and G. Peterson, "Ecological cross-scale interactions," in Ecosystem-based management for the oceans, K. McLeod and H. Leslie, Eds., pp. 74-91, Island Press, Washington, DC, USA, 2009. 

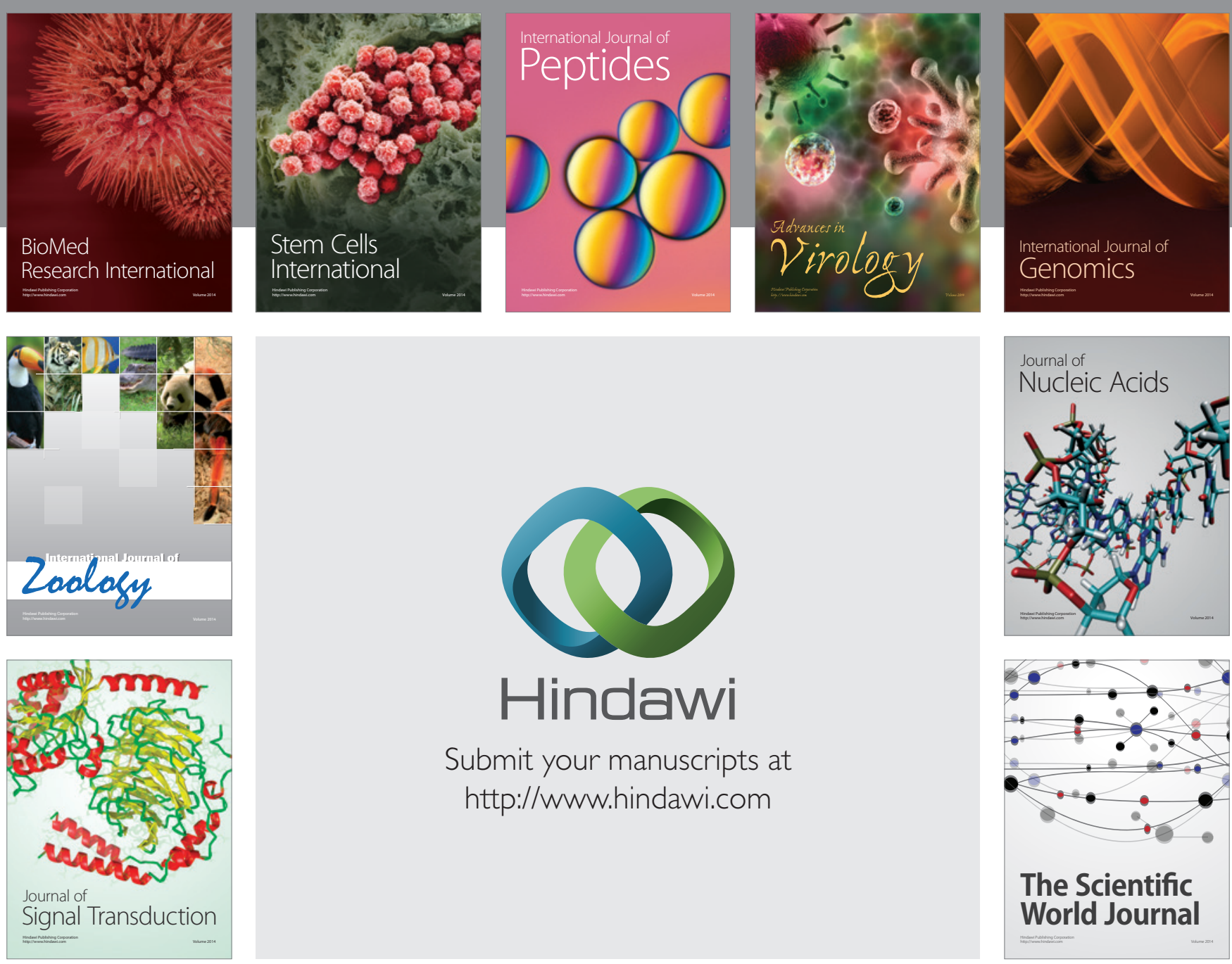

Submit your manuscripts at

http://www.hindawi.com
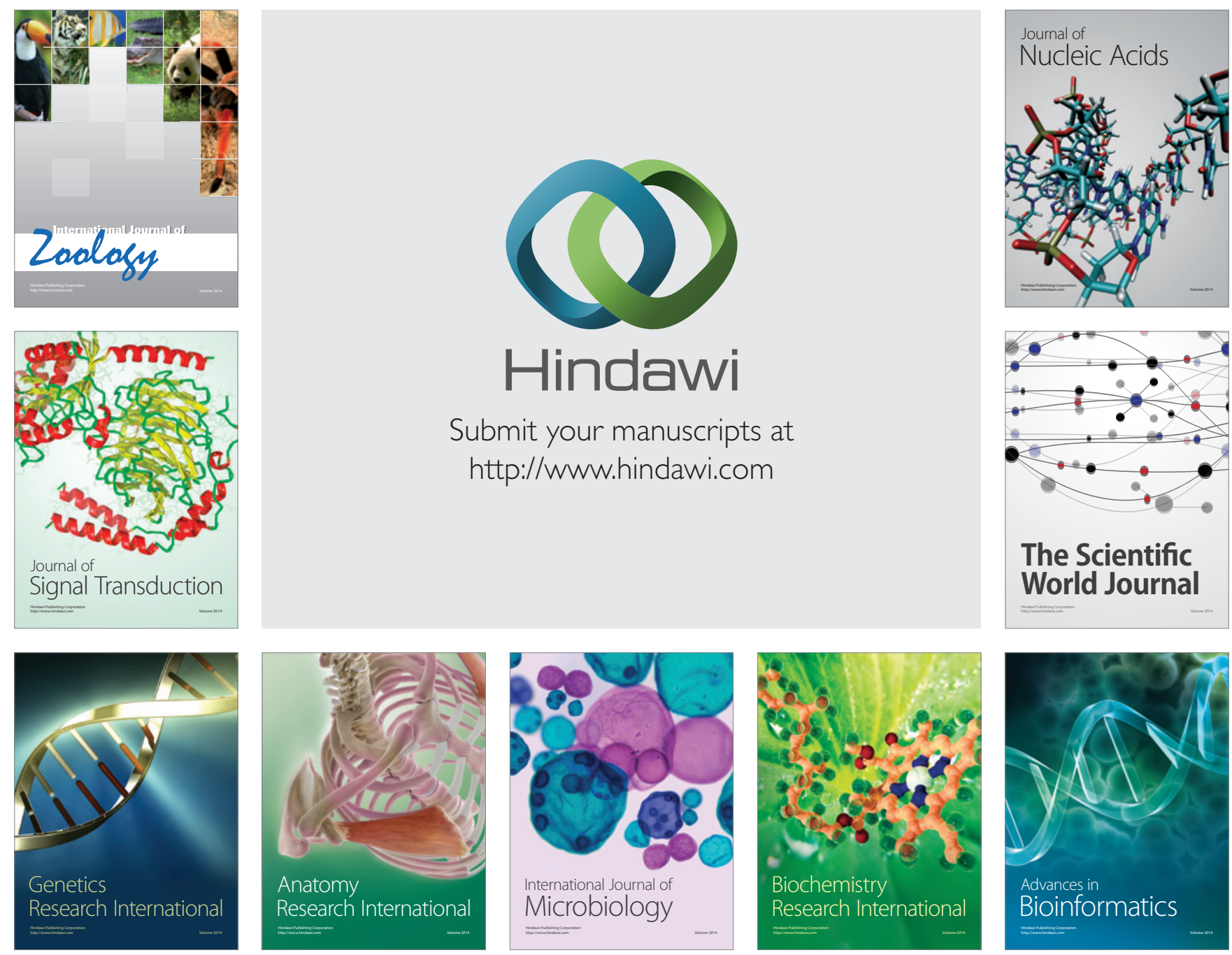

The Scientific World Journal
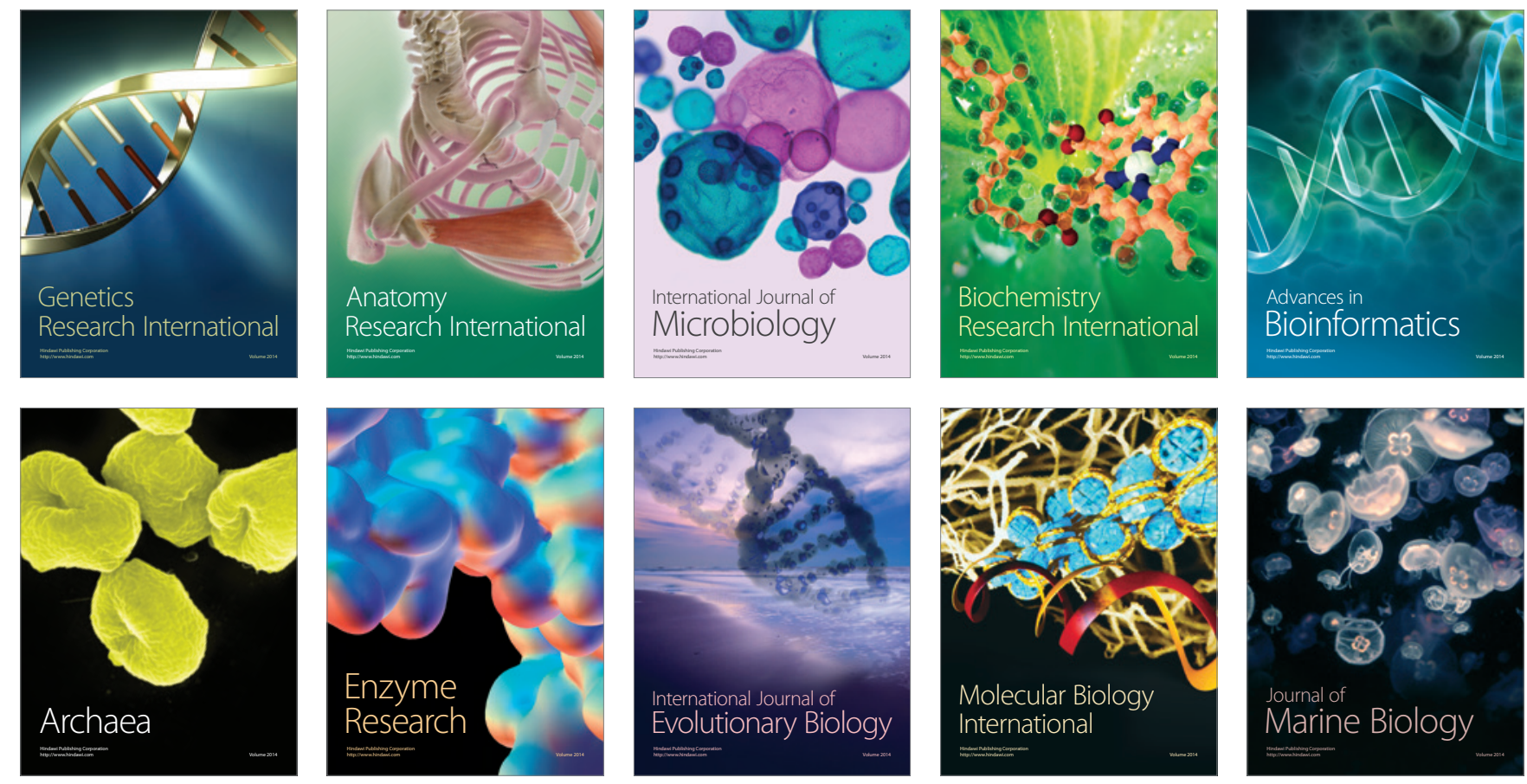